\title{
“...Y LOS DICHOS ESPAÑOLES ESTARÍAN AMANSEBADOS Y HARÍA CASTA MALDITA DE MESTISOS..."**
}

\author{
Eliane Garcindo de Sá \\ PPGHIS - Departamento de História - UERJ
}

PEA- Programa de Estudos Americanos IFCS/UFRJ - Pesquisadora Associada

\section{Resumo}

Este artigo propõe uma reflexão sobre a construção histórica de sistemas simbólicos de identidade cultural, étnica e religiosa entre distintas sociedades, tomando como referência as condições estabelecidas nas circunstâncias da colonização espanhola na América, a partir do olhar do cronista andino Felipe Waman Poma de Ayala. Observa-se a constituição de mecanismos defensivos diante das ameaças do estranhamento imposto pelo contato.

\section{Pallavros-Chave}

Maldição • Mestiço • Mestiçagem • Mediação • Identidades

\section{Abstract}

This article proposes a reflection about the historical buildt of symbolical systems: cultural, ethnic and religious identity in between different societyes. It takes the established conditions along the Spanish colonization in America from the perception of the andean chronist Felipe Waman Poma de Ayala. The Constitution of defensive mechanisms towards the threaten of the unknown is observed. These mechanisms are a consequence of this contact.

\section{Keywords}

Curse $\bullet$ Mestizo $\bullet$ Miscegenation $\bullet$ Mediating $\bullet$ Identities

* Este texto foi escrito em 2003, visando sua incorporação numa coletânea em torno do tema "malditos", cuja publicação finalmente não se efetivou. O dossiê da Revista de História pareceu à autora ser uma oportunidade de discussão das reflexões que se dirigem para o universo colonial americano, no enfrentamento entre os elementos das sociedades nessa zona de contato. 


\section{Tecendo a trama da maldição}

A maldição é uma sorte de exorcismo. Amaldiçoar é afastar do convívio, negando reconhecimento a algo ou alguém em discordância com nossos propósitos; eliminar alguém que pode espalhar entre nós o mal que não desejamos. Quando amaldiçoamos estamos negando aconchego e compreensão. A ameaça que o amaldiçoado representa não permite qualquer aproximação. Ele merece não apenas o castigo do afastamento, deve ser execrado. A ele serão negadas quaisquer prerrogativas, o privilégio do pertencimento ao coletivo, o usufruto do pacto identitário. Ele não é um dos nossos. É o inimigo que destruímos simbólica e socialmente, quando não fisicamente. Nós o identificamos pelas diferenças, que o negativizam e fazem-no merecedor de nossa intervenção destrutiva. O maldito não pode passar desapercebido : deve ser identificado e punido.

A maldição é, pois, uma construção simbólica cujas origens se relacionam à incompreensão, ao medo, ao irracional. Ela se constrói sob condições históricas que podem indicar seu percurso de construção, consolidação e atuação. As decorrências objetivas da maldição se manifestam através de quem amaldiçoa, por seus atos, justificativas, seu protagonismo enquanto denunciante. Os efeitos sobre o maldito implicam em que seja marcado e isolado e/ou destruído por meios pertinentes.

Reconhecer e perseguir o maldito exigem a produção de um perfil, explicitação estereotipada de seu comportamento. Algo deve indicar e identificar rápida e eficazmente o maldito : pequenos traços e sinais devem acionar o alarme das defesas e impedir o ataque pressuposto. Identificado com prontidão, o maldito não deverá agir, mas ser surpreendido pela ação preventiva e anti-séptica do bendito, do escolhido que vela e preserva a unanimidade e o consenso de uma identidade intransigente. $\mathrm{O}$ inimigo, maldito, é então uma referência que reforça o grupo e o combate ao maldito e à maldição mais um fator de aglutinação interna.

Para que se consolide uma estrutura social capaz de atuar articuladamente, definindo a maldição e o maldito, criando sistemas eficientes de busca, identificação e destruição, é preciso, entretanto, que as convicções e os argumentos que definem o mal sejam partilhados por significativos e atuantes setores da sociedade. $\mathrm{O}$ maldito é um inimigo coletivo.

As condições históricas em que se geram e instalam sistemas de defesa contra ameaças a outros específicos, classificados como malditos, se reportam não só a interesses imediatos materiais, mas a sentimentos, desconfortos, situações de privação de prestígio ou ameaça de privações. Momentos de crise sociais, a intensificação da 
presença de fatores que gerem inseguranças profundas entre os membros de um grupo, podem transformar antigos aliados em inimigos amaldiçoados.

$\mathrm{O}$ viés religioso fundante no ato de maldizer, como privação do acesso ao divino, tem uma forte conotação, mas esta não é a única expressão do ato. Em sociedades laicas, a privação por mais terrena não atenua o ato e suas consequiências. A perseguição obstinada ao maldito, entretanto, parece guardar sempre ares de seita.

Curioso é que o maldito está quase sempre em condições desvantajosas em face de seus detratores. Não acredita, talvez, no poder da sua atuação e, embora possa resistir, não está pronto para reverter uma hegemonia que já ameaça.

Outro aspecto interessante quando se enfrenta o tema é observar que a análise da construção do perfil do maldito e da sua eleição em determinados contextos demonstra que a escolha do inimigo pode ser enganosa. As divergências estariam mais explicadas por circunstâncias históricas que criam condições precárias gerais para as sociedades, mas os sentimentos, os arranjos casuais, desassossegos, atos espontâneos e impensados, podem configurar situações de confronto irreversíveis entre partes.

O maldito pode ser, por sua parte, um agressor, assim identificado por sua atuação objetiva como agente conquistador e dominador. Em tais circunstâncias, o equilíbrio de forças defensivas contra o amaldiçoado desfavorece aquele que amaldiçoa. Táticas eficazes para expressar a maldição de vencidos e/ou submetidos contra seus algozes estão limitadas por condições de força, que dificultam a perseguição e segregação ostensivas.

O espaço da maldição é um terreno fértil para a manipulação ideologizada dos valores, significados e sentimentos, afetos e desafetos, já que, diante das difíceis circunstâncias do convívio social, é possível sempre apontar para a intransigência em detrimento da transigência.

Não se trata de caminho fácil aquele que busca entender e respeitar o outro, aquele que diverge, sobretudo se o outro se impõe pela força e pela dominação, gerando reações genericamente fundamentalistas. Sob condições de ameaças concretas e práticas de conquista e dominação acirram-se as possibilidades de divergência e intransigência.

Ao historiador cabe a tarefa de esmiuçar e expor as condições de construção das maldições e a eleição dos malditos, como referência contínua sobre a condição humana. Talvez, conhecendo melhor os seres humanos, possamos ser seres humanos melhores. 
Nosso objetivo aqui é observar a expressão de um fenômeno de maldição manifesto no âmbito da sociedade colonial hispano-americana, quando e onde sociedades de profunda desigualdade entre as partes em confronto e situação de conquista militar e cultural constroem elementos novos e constituem sociedades mestiças. Não só os sistemas culturais se permeiam, em novas abordagens sócio-históricas, híbridas e de profundo estranhamento, complexidade e diversidade. Nesta construção se formam novos contingentes : criollos, mestiços, negros, mulatos, zambaígos. Quando observamos os atributos que permitem tais classificações entre grupos que se distinguem, ficam evidenciados critérios de agregação sustentados por representações relacionadas a estereótipos etnico-biológico/fenotípicos e sócio-culturais.

Entre conquistadores e conquistados, colonizadores e colonizados permeavam sistemas simbólicos de identidade cultural, étnica e religiosa excludentes e intransigentes, sob a supremacia técnica e militar dos conquistadores espanhóis.

Se entre os conquistadores o reconhecimento dos novos contingentes - mestiços, sobretudo, e com especificidade, os que resultavam das relações entre, conquistadores-espanhóis/conquistados-indígenas - se caracterizou não só por perplexidades e ambigüidades, mas por segregação e exclusão, a voz de um índio cronista andino apontou uma expressão radical na rejeição ao mestiço identificado como casta maldita.

A dolorosa manifestação de Felipe Waman Poma de Ayala sobre a desagregação do universo andino pré -hispânico, exposta em Primer nueva coronica y buen gobierno ${ }^{1}$, escrito no início do século XVII, traz uma avaliação negativa do mestiço, ao qual chega a imputar grande carga de culpabilidade no processo de desestruturação da sociedade incaica, demográfica e culturalmente. O cronista enuncia uma doutrina : identifica e detecta termos da condição maldita que atribui ao mestiço, aponta as origens desta condição e prevê medidas preventivas. Elemento pernicioso, que deveria ser afastado do convívio com os indígenas, é o mestiço ameaçador das tradições originais indígenas, fruto de amancebamento, pecado grave no contexto da evangelização colonizadora. Condenado pela ilegitimidade, o mestiço não tem lugar definido; condenado pela dupla origem diante de referências de estruturas sociais rígidas, não merece, portanto,

${ }^{1}$ Felipe Guaman Poma de Ayala [Waman Puma] - El Primer Nueva Corónica y Buen Gobierno (1612-1615/1616), 1a. edição crítica de John Murra e Rolena Adorno, México, Siglo XXI-Nuestra América, 1990. 
reconhecimento social. Poma ainda enfatiza os efeitos maléficos da inserção do mestiço que se estendem ao universo hispânico.

A direção que vai se definindo nas formas de colonização, a inviabilidade de controle das relações entre as sociedades em confronto, o desequilíbrio de forças entre os conquistadores e os conquistados são, sem dúvida, fortes impedimentos à implementação de uma doutrina de segregação forjada e orientada pelo contingente submetido. Esta contingência não significa, entretanto, que tal doutrina não representasse um sistema referencial para parte da população indígena e que fragmentos, e muitas vezes não apenas fragmentos, do arcabouço de argumentos em que se sustentou não persistissem larga e longamente nas sociedades mestiças.

\section{Casta maldita}

A mestiçagem, processo étnico-cultural, resultado observável do convívio entre grupos humanos de distintas origens, auto-identificados como distintos, marca a trajetória histórica das sociedades desta América. O número de mestiços cresce intensamente a partir dos primeiros contatos, facilitados no caso espanhol pela barragania, autorizada no Código das Siete Partidas, século XIII, devido à desproporcionalidade de mulheres espanholas. Do lado "indígena", facilitado por diversos costumes e por condições propiciadas diretamente pela conquista. Assim, inicialmente os contatos, uniões entre conquistadores e conquistados serão incentivados.

Para os colonizadores espanhóis o crescimento numérico dos mestiços rapidamente transforma-os em ameaça. O Vice-Rei Nieva observa que "Os mestiços são em tão grande número e suas inclinações tão más que provocam agitação". O Vice-Rei Toledo explicita os riscos : "Os mestiços reivindicam a posse do país devido a sua dupla herança, materna e paterna” ${ }^{2}$.

Toledo busca, através de medidas práticas, conter os percursos descontrolados da conquista e colonização, regulando a distribuição espacial entre índios e espanhóis, e a presença de uns entre outros.

A administração colonial está atenta aos perigos e ameaças à dominação. Sobretudo na região andina, e nas proximidades de Cuzco, as relações entre a antiga nobreza incaica e mestiços parece constituir, mais que em qualquer parte, uma ameaça latente.

${ }^{2}$ MAHN-LOT, Marianne. A Conquista da América Espanhola. Campinas: Papirus, 1990, p. 87. 
Em nenhum momento a aceitação social do mestiço é consensual. A qualidade mestiça é sempre desabonadora entre espanhóis. Sobre filhos de espanhóis com a aristocracia indígena foi possível entender que se tratava de "homens de bem que não se deve chamar mestiços", "pois não era tanto o sangue quanto o modo de vida que distinguia os brancos dos mestiços (e ainda mais dos índios) ${ }^{3}$.

Aqueles que estão mais afastados do contexto hispanizado ou identificados com os setores desqualificados da sociedade colonial, andantes, vagamundos, constituem elementos de insegurança e são alvo de constantes reivindicações de controle, seja pela educação das crianças, seja pela repressão dos adultos, por parte de autoridades civis e eclesiásticas e de vizinhos.

Um contingente, hispanizado, escolarizado, de mestiços muito cedo reivindica um papel mediador no processo de hispanização, como funcionário da administração ou como religioso ${ }^{4}$.

O reconhecimento posterior deste papel no processo de colonização e criação de novos grupos étnicos, novas sociedades, novas culturas e identidades se fará por meio do testemunho de um mestiço, a partir da Espanha : O Inca Garcilaso de la Vega escreve e publica sua obra na Península Ibérica. O filho de uma nobre inca e um fidalgo espanhol, por seu destino incomum, possibilitou a sedimentação do papel mediador do mestiço e permitiu a criação de um mito que se contrapõe aos demais testemunhos de mestiços, e sobre mestiços, produzidos desde a conquista.

A narrativa deste processo de representação do mestiço produzida pelo Inca Garcilaso de la Vega mereceu vários estudos, seja pelo papel que escolheu como tradutor entre culturas, mais ainda pelo caráter, publicação e difusão de suas obras de tradução e história. Diante de condições específicas construiu uma trajetória, e protagonismo do personagem mestiço, que fundou e fundamentou uma referência original para a representação do mestiço num mito com o qual se confunde.

No século XVII, proibida de circular na América, a obra de Garcilaso, leitura de líderes da independência, é relida a cada século. "Los comentarios reales de los Incas", sobretudo, é um instrumento que consolida a representação do mestiço ideal, mitologizado.

\footnotetext{
${ }^{3}$ Idem, p.86.

${ }^{4}$ Ver ARES QUEJIA, Berta. El papel de mediadores y la construcción de un discurso sobre la identidad de los mestizos peruanos (siglo XVI) In: ARES QUEIJA, Berta \& GRUZINSKI, Serge. Entre dos mundos: fronteras culturales y agentes mediadores. Sevilla: s/ed., 1997, p.37-59.
} 
As condições sob as quais Garcilaso preserva o orgulho de suas origens são muito distantes daquelas experimentadas por inúmeros mestiços que vivem no Vice-reino do Peru, como nas Índias em geral, ou na metrópole, reivindicando reconhecimento e direitos. Na Espanha, local que escolhe para viver, respaldado por alguns privilégios que decorrem de sua origem paterna se distancia cada vez mais daqueles mestiços identificados como vagabundos, ou os que desaparecem no universo indígena ${ }^{5}$. A imagem do mestiço que Garcilaso contribuiu para fixar guarda distâncias crescentes com a multiplicidade de representações que permearam a inserção do contingente mestiço nas novas relações.

A imagem de um mestiço idealizado, no entanto, pode constituir um mito fundador, na confluência de origens e destinos da hispanidade. Garcilaso é o elemento que permite a superação de traços negativos no desenho do mestiço ideal, através do predomínio da expressão cultural que lhe atribui e que permite redimensionar o significado do termo e a imagem. Se a situação social particular de Garcilaso o distingue marcadamente de outros mestiços, mesmo daqueles oriundos das elites colonizadoras e colonizadas como consequiência da trajetória que seguiu na Espanha, o caráter de síntese cultural que simboliza passou a constituir referência obrigatória no universo de representação do mestiço. Garcilaso é aquele que não renega suas origens e que se colocando no centro do poder metropolitano, recorre aos códigos e recursos disponíveis, para, identificado com o projeto hispanizador e evangelizador, resgatar o passado e buscar o reconhecimento do Tahuantinsuyo. O capitão das lutas contra os mouros em Granada, religioso e homem de letras do universo renascentista demonstra-se capaz de traduzir o mundo andino e espanhol, um ao outro, organizando o caos do confronto numa narrativa que o ordena e disciplina, dando-lhe inteligibilidade. Celebrado objeto de estudos de múltiplos enfoques, Garcilaso resume com propriedade o mito mestiço. Este mito serve posteriorimente a propósitos vinculados ao enunciado de identidades forjadas sobre o caráter das sociedades latino-americanas.

Do ponto de vista da ocidentalização/hispanização, o processo de mestiçagem, no sentido amplo do termo, toma intensidade e o papel de mediador atribuído a setores mestiços, comprometidos com esta via de civilização/trans-

\footnotetext{
${ }^{5}$ A permanência de mestiços vivendo entre os indios, a sua maneira, modo de vestir, de cortar o cabelo, identificado como mestiço por um recenceador, pode ser confirmada por informações constantes no censo realizado em 1613. Ver COOK, Noble David. Padrón de los indios de Lima en 1613. Lima: Universidad Nacional Mayor de San Marcos, 1968.
} 
culturação, deixará traços retomados posteriormente na construção de identidades regionais e nacionais na América Latina. O caráter mestiço será um traço delimitador da novidade americana. Garcilaso pode constituir referência fundante do continente/contingente mestiço.

Esta é uma possibilidade dos usos do passado. Há que argüir, no entanto, a complexa e conflitante trama de referências produzidas concomitantemente na formação das sociedades hispano-americanas. Outras abordagens e projetos antigos e/ou contemporâneos podem ganhar visibilidade neste quadro.

A intensidade do processo de mestiçagem e o aumento numérico de mestiços, desde cedo observado, a que já nos referimos, parece apontar para uma situação paradoxal, onde estão presentes aparentes contradições entre as interpretações predominantes, de representações, atribuições, reconhecimento de papéis sociais e a efetiva relação entre os grupos em contato, que vão conformando uma sociedade crescentemente "mestiça".

Na sociedade hispano-peruana, como na sociedade colonial hispano-americana, em geral, o "mestiço” foi uma invenção necessária para representar algo novo. Esta sociedade que se caracteriza pelo enfrentamento da diversidade, pela (re)invenção dos fragmentos originários de sistemas culturais em confronto e (re)construção, engendra o fruto biológico deste encontro/confronto : a concretização da relação sócio-político cultural entre o conquistador, sujeito da cultura expansionista cristã, branco, e o conquistado, sujeito da cultura invadida idólatra, "índio" - o mestiço. O novo elemento introduzido nas novas sociedades, nos sistemas simbólicos das partes atuantes, terá múltiplas e conflitantes formas de inserção e representação.

A multiplicidade, ambigüidade, perplexidade, difícil e complexa construção sóciohistórica das novas sociedades e de seus diversos e distintos componentes, de acordo com a variedade das condições, papéis e interesses sociais experimentados nas trajetórias históricas, têm sido evidenciadas em vários estudos sobre o mestiço.

A percepção da introdução e inserção do mestiço através da perspectiva das sociedades andinas é uma questão estimulante. Derrotadas militar e politicamente as sociedades "indígenas" ofereceram resistência cultural inegável,

\footnotetext{
${ }^{6}$ Sobre este tema remetemos ao estudo da autora, Mestiço: entre o mito a utopia e a História, Rio de Janeiro, 2001 - versão impressa. São referências obrigatórias as obras de Serge Gruzinski, com especial menção, O Pensamento Mestiço. São Paulo: Companhia das Letras, 2001.
} 
mas a explicitação das versões interpretativas dos processos experimentados por estas sociedades não dispôs de condições de expressão e divulgação semelhantes às que se oportunizaram para os vencedores.

Como reagiram, por exemplo, as comunidades que viram nascer dentro de seu espaço os filhos dos conquistadores que passaram e deixaram seu sêmen nas mulheres violadas ou participantes desejosas de atos sexuais fortuitos ou mesmo em relações de precária estabilidade?

Como se comportariam os velhos diante da presença e atuação de descendentes de hábitos e aparência estranha?

Por que muitos mestiços se postavam, vestiam-se e penteavam-se à moda indígena, enquanto outros buscavam deliberadamente a hispanização?

Sabe-se que parte da elite indígena encontrou na aliança com o conquistador a continuidade de uma prática tradicional e buscou a garantia da manutenção de privilégios. Os mestiços que resultaram destas alianças tiveram situações também privilegiadas, mas sua inserção não se fazia com plena igualdade com a elite espanhola. $\mathrm{O}$ nascimento de filhos mestiços não garantia às nobres incas o casamento com os fidalgos conquistadores, o que mantinha estes filhos mestiços em situação indeterminada.

A quebra das linhagens originais provocada pelas relações entre os conquistadores espanhóis e as mulheres índias foi sentida fortemente, na medida em que expressava a perda do poder destas elites e que os mestiços, frutos destas relações, representavam uma aliança com o conquistador, não se equiparavam com ele.

A dominação se evidenciava e consolidava, ainda, com a desagregação do sistema de relações de gênero, através da supremacia do homem espanhol, agora senhor das mulheres indígenas, gerando filhos seus. Da desagregação de um sistema demográfico surgia outro, que se configurava no mestiço - sinal contundente da presença e da dominação. Que leitura podia ser feita a partir das referências e critérios de reconhecimento sócio-culturais tradicionais indígenas sobre esta situação imposta?

O papel mediador reivindicado por determinados contingentes mestiços pressupôs sempre a aceitação da colonização, da superioridade da cultura alienígena. Constituía-se num patamar de hegemonia do colonizador.

Se, entre esta hegemonia e o reconhecimento do passado incaico Garcilaso se diz mestiço a boca llena, essa declaração encontra contraposição radical na afirmação de Felipe Waman Poma de Ayala que dá título ao presente artigo.

Poma, o índio que nunca deixou o universo andino, de outro lugar, reconhece no mestiço o indesejável - casta maldita. 
O reconhecimento do mestiço como maldito tem, sem dúvida, no contexto em que se expressa, notória influência da orientação jurídico-religiosa castelhana, como argumento de legitimação. Esta referência indica, porém, apenas um sinal em um sistema de representações produzido sobre o complexo enredo da conquista e colonização, consubstanciada na narrativa de Poma.

A convergência do argumento do cronista, que aponta a origem da condição da maldição na ilegitimidade, com a justificativa da ilegitimidade alegada na república espanhola, para negar reconhecimento aos mestiços para exercerem cargos ou usufruírem direitos pretendidos, constitui um ponto estratégico na argumentação. Permite a extensão das considerações negativas que enfatiza no mestiço aos vários universos em que este transita, estendendo e aprofundando o argumento.

O detalhamento da atuação social, apresentado concomitantemente ao enunciado da avaliação ética, a qualificação do mestiço face à moral cristã, presentes no texto de Poma, expõe e enfatiza o caráter negativo e pernicioso do mestiço, indicado por atributos em que se salienta a ameaça que representa para a tradição indígena : dissoluto, ladrão, preguiçoso, desleal, traidor, aproveitador, destruidor. Estas características se associam à ilegitimidade.

A atribuição pelo autor destas características a um determinado e inventado grupo étnico pode ser relacionada com a percepção do trânsito do mestiço entre as sociedades em relação, pela fluidez de sua atuação e presença, como através da possibilidade de aparecimento e desaparecimento em diferentes lugares, numa e outra ponta dos universos culturais, decorrente de condições de suas características fenotípicas, conjugadas ao domínio de códigos distintos. Da percepção desta condição de múltiplo acesso do mestiço parece derivar a avaliação de uma superioridade tática ameaçadora e a dificuldade de enfrentamento e aceitação/incorporação do mestiço, que aparece como dissolvente da identidade indígena referente. Nesta circunstância o mestiço deve ser afastado, eliminado.

Deve-se observar que, diante da ameaça de destruição da tradição indígena, Poma, enquanto desqualifica o mestiço - tipo étnico-biológico - como mediador, qualifica a si mesmo como tal. Uma condição para o desempenho do papel mediador está, entretanto, dependente do acesso ao outro - ao rei, ao hispânico e, portanto, ao domínio dos códigos do outro. Ora, esta prática de mediação e tradução torna-se inerente às práticas das sociedades mestiças que se forjam no confronto. Serge Gruzinski cunhou o conceito de "pensamento mestiço" para indicar o fenômeno da produção do pensamento construído com 
base em sistemas de representação e referências fragmentárias, múltiplas e diversas, na interseção entre códigos culturais diversos. Em condições de contato e convivência, em âmbito mundial, a partir do processo de expansão européia iniciado no século $\mathrm{XV}$, as sociedades interagem e produzem, a partir de elementos disponíveis, buscados entre culturas originárias e das culturas de novo contato, um repertório de símbolos e sinais novo e híbrido, radicalmente. Já não é possível pretender isolamento diante da incorporação e do domínio de fragmentos múltiplos e vários, que permitem o entendimento e a ordenação do pensamento e novas cosmovisões.

A mediação, aí, parece constituir condição imponderável. O reconhecimento do caráter mestiço desta construção não será, entretanto, estendido a todo o conjunto de sociedades e sistemas culturais envolvidos.

As complexidades e perplexidades destas construções darão origem a expressões de pensamento híbrido, muito mais identificáveis quando obrigam à convivência de formas distintas e alheias aos referenciais ocidentais.

Estas condições podem ser observadas no texto de Poma, necessariamente expressão de pensamento mestiço, visando alcançar por incorporação de códigos novos - códigos do conquistador/colonizador - a possibilidade de mediação/tradução de interesses/valores tradicionais à cultura andina. Neste percurso constrói para o mestiço, identificado como casta, como grupo étnico distinto - reconhecido como categoria híbrida -, a imagem da referência central na dissolução não só das tradições andinas e hispânicas, mas do desaparecimento físico dos índios.

Poma se expressa através de um discurso em que se serve de diversos sistemas lingüísticos (espanhol, quechua, aymara) e, portanto de distintas referências culturais de que se reapropria e rearticula, bem como de desenhos em que manifesta também esta multiplicidade, numa construção em que todos os elementos se redimensionam para expressar a condição ímpar da transculturalidade que se efetiva nas circunstâncias da conquista/colonização.

"El primer nueva corónica y buen gobierno" é um texto dirigido ao rei de Espanha em que o autor apresenta uma narração das condições em que se encontra o reino do Peru, sob a administração colonial, em paralelo com as condições anteriores à presença dos espanhóis. Diante da avaliação negativa, dos riscos e prejuízos, seja para o rei, seja para o reino, sobretudo o desaparecimento dos índios, propõe medidas que julga capazes de impedir o desastre que prevê e salvar o reino, para bem do rei e dos súditos.

Diante da extensão do texto e de sua complexidade, embora o autor pretenda ver na obra uma nova forma de crônica de Índias, López-Baralt consi- 
dera que "El primer..." é uma obra híbrida : "carta ao rey, memorial de peticiones y remédios, tratado de derecho, crónica de Índias ilustrada, manual para predicadores y libro de consejo de príncipes emparentados con la emblemática política europea"7.

López-Baralt salienta que ao iniciar a carta o autor anuncia, o procedimento a ser adotado :

utilizar los principios éticos cristianos e incluso mucho de la metodología y retórica de catequización visual puesta en boga por Trento para promover su programa de buen gobierno. Más que convertir a los infieles le interesa mover $<$ los animos y consencias de los cristianos a que muden sus vidas > (entiéndase : den un trato mejor al indio andino), y no duda en invocar $<$ grandes castigos $>$ de Dios para sustentar un argumento de por si profundamente político ${ }^{8}$.

Ainda, tendo o rei como destinatário não pretende agradar simplesmente com sua arte visual, mas convencer. A carta é também memorial de protesto e medidas, enviada a quem tem o poder de encontrar soluções. Para López-Baralt, Poma transforma sua obra em "memória", com a finalidade de ver a justiça, quando faz dos desenhos o eixo que sustenta o discurso. ${ }^{9}$

Rolena Adorno recupera do prólogo com que Poma conclui seu "diálogo con el rey" a seguinte citação que é, por si só esclarecedora e dolorosa :

Digo a Vuestra Sacra Católica Majestad, llorando y clamando, dando boses el cielo pidiendo a Dios y a la virgen María y todos los santos y santas ángeles. Digo que nosotros pobres nos enbía tantos castigos y

${ }^{7}$ LÓPEZ-BARALT, Mercedes. Icono y conquista: Guamán Poma de Ayala. Madrid: Hiperión, 1988, p.27.

${ }^{8}$ Idem, p. 282.

${ }^{9}$ Idem, p. 282.

${ }^{10}$ Felipe Guamán Poma de Ayala (998-999) 1615. Apud ADORNO, Rolena. Cronista y príncipe. La obra de don Felipe Guamán Poma de Ayala. Lima: Fondo Editorial de la Pontificia Universidad Católica del Perú. 1992, Segunda edición, p. 226, 225. 
malauenturas y destruciones : Dios y vuestra Magestad en el permita que nos acauemos y se despueble su rreyno. ${ }^{10}$

O cenário constante que transparece na leitura da obra é a perplexidade diante das condições da conquista e colonização, enquanto fazem desaparecer a ordem anterior.

Um dos aspectos essenciais na proposição de Poma é o estabelecimento de uma relação direta com o rei, eliminando as instâncias intermediárias que seriam responsáveis diretas pela destruição dos índios, de suas condições de vida e de diminuição de riquezas para o rei. Uma aliança com o rei, com a consideração e o reconhecimento da aristocracia indígena, a recomposição da rígida estrutura social anterior, poderia garantir o controle social e a dominação dos contingentes chamados "bajos" por Poma. Não se afasta, mas pelo contrário se enfatiza a intensa cristianização e hispanização através da aprendizagem da língua espanhola, da escrita, mas resguardando tradições andinas que assegurassem a preservação de estruturas sociais, poderes e práticas de controle e sobrevivência de condições de reconhecimento, identidade e manutenção de lugares e papéis que deveriam ser mantidos.

A construção de Nueva Coronica resulta numa versão da memória e da história construídas na trajetória de Poma. Educado em Cuzco capacita-se como intérprete, isto é, tradutor, mediador. Nesta condição acompanha o visitador eclesiástico Cristóbal de Albornoz. Ao que parece, atuou em comissões no Terceiro Concílio de Lima e exerceu o cargo de escrivão ou secretário en Quinua. ${ }^{11}$

As atividades que exerce não só possibilitam o trânsito entre códigos diversos, mas oportunizam a observação das condições sob as quais a população indígena estava submetida no processo de conquista/colonização. Um interessante aspecto relacionado à condição mestiça dos agentes indígenas no processo observado, é parte da construção de representações que denunciam esta condição. Salvando da morte o capitão Luis Avalos de Ayala, Martín Mallqui, pai de Poma, adquiriu o sobrenome de Ayala. Observa López-Baralt : "El apellido español, junto a los reclamos de descender de las dinastías incaicas y yarovilca y el nombre

\footnotetext{
${ }^{11}$ LÓPEZ-BARALT, Mercedes. Op. cit., p. 67/71.

${ }^{12}$ Idem, p. 70.
} 
probablemente totémico de Guamán Poma (halcón/puma) parecen subrayar su condición auto-impuesta de mediador entre culturas". ${ }^{12}$ Esta condição não é, entretanto, entendida ou reconhecida no seu caráter mestiço pelos agentes.

É impossível não se considerar o papel que indígenas representaram como mediadores, como colaboradores, seja como "linguas", como articuladores políticos de alianças, seja por outras formas de atuação. Esta é, ao que parece a pretensão mesma de Poma. É na condição de mediador com o rei que escreve sua carta-crônica, "conselho de príncipes aparentados com a emblemática política européia". ${ }^{13}$

Na construção dos sistemas de reconhecimento engendrados, então, a reivindicação deste papel, implicando em inserção social possível, foi uma pretensão explícita de mestiços. Admitido pelos espanhóis, com reservas, podia ser função reconhecida para aqueles que demonstravam qualidades culturais e/ou parentesco que permitissem compatibilizar suas presenças nas estruturas sociais em formação, em condições que neutralizassem riscos aos padrões de controle social rígido desejados. Nem mesmo a nobreza indígena foi jamais incorporada à república dos espanhóis e sua atuação mediadora, mesmo quando explicitamente colaboradora com o projeto de colonização, possibilitou seu reconhecimento no âmbito da sociedades colonial. A instransponível distinção de origem, na medida em que determinava pertencimentos à identidades distintas, afastadas, fazia incompatível a aproximação e, portanto, a possibilidade do reconhecimento do pertencimento a uma referência comum e do papel mediador para os índios.

Da mesma maneira, por parte dos índios - apartados dos sistemas de poder e controle pelos espanhóis, marcados como "outros", impossibilitados de passarem por desapercebidos e/ou se confundirem entre membros da república dos espanhóis, o que aliás também não seria sempre uma condição desejada - tornava-se complexo o reconhecimento dos novos papéis. Tanto ou mais difícil seria reconhecer, no sentido de vincular lugar de valor, o caráter híbrido das novas práticas simbólico-culturais a que lhes obrigava a dominação.

Nestas circunstâncias, temos que na sociedade colonial o reconhecimento como atores mediadores aos índios esteve comprometido por valores e sentimentos diversos.

Para aqueles que como Poma guardavam referências de honras e privilégios "aristocráticos" e orgulho de um passado, que o presente transformava duramente

${ }^{13}$ Idem, p. 271. 
em apenas memória, reconhecer e reconhecer-se numa identidade compósita, demarcada pela interferência imponderável de um outro resulta num esforço de entendimento inalcansável. Tal esforço se pode observar através da produção e da narrativa em que se expressa. Em meio ao caos de desagregações e (re) construções parece impossível conciliar tantas forças que se chocam.

A obra de Poma representa um esforço incomensurável de entendimento, de (re)ordenamento e (re)visão de universos. A proposição que apresenta vai muito mais além da crônica, tal como praticada no âmbito da cultura da conquista e da expansão das monarquias ibéricas. Sob o pretexto da defesa do reino para benefício do rei, Poma emite um contundente grito de revolta e protesto contra o desaparecimento da tradição original pré-hispânica andina.

Poma não nomeia expressamente o projeto conquistador espanhol como responsável pela desagregação que denuncia, mas a forma pela qual se realiza. Não se pode excluir a possibilidade de que assim procedesse como recurso tático. O fato é que, faz uma transparente radiografia da colonização, dos agentes colonizadores e dos efeitos da colonização entre os indígenas, para atingir a sensibilidade do rei.

A si mesmo reserva o papel de denunciante, desqualificando outro sujeito em que não reconheça a pureza do pertencimento à elite indígena, na qual se situa. Isto pressupõe qualidade superior para agentes que possam dialogar como iguais. A tensão decorrente do estranhamento provocado pela conquista/colonização através da convivência dos distintos é transferida para a expressão étnico-biológica que materializa a relação imposta - a casta de mestiços, nova referência inventada para indicar os seres engendrados nas relações sexuais entre grupos distintos, mas equivalentes.

A denúncia reserva ao denunciante uma função protetora e de salvaguarda diante das ameaças que enuncia. Afasta o denunciante do denunciado pela pressuposta superioridade do primeiro, zelador de princípios de verdade absolutizados.

O pressuposto da estrutura explicativa construída pode ser, no caso, encontrado no enunciado do repúdio que expressa Felipe Wama Poma de Ayala sobre

\footnotetext{
${ }^{14}$ Felipe Guaman Poma de Ayala. Apud: DAYRELL, Eliane G. O índio e o imaginário americano: enfrentamento, ameaça ou solução?. Colóquio Internacional ADLAF-AFSSALEl Indio como sujeto y objeto de la Historia Latinoamericana pasado y presente. Universidad Católica de Eichstätt, 25-28 outubro de 1995, p. 2, texto datilografado.
} 
qualquer forma de "miscigenação" : "para ser buena criatura de Dios, hijo de adán u de su muger Eua, criado de Dios, español puro, yndio puro, negro puro." 14

Este princípio sustenta coerentemente a exposição e argumentação durante o texto, em que especificamente os mestiços - filhos de espanhóis(olas) e índios (as) se destacam como elementos dissolventes destruidores das antigas tradições.

Aí está a indicação de um ponto central da denúncia - o efeito concretizado da política efetiva de dominação posto em contestação : em que os mestiços, casta maldita, associados aos males impostos aos índios, são percebidos como sujeitos (instrumentos) destruidores do universo indígena :

Don Francisco de Toledo dexó mandado una de las santas cosas en servicio de Dios y de su Magestad y bien de los pobres yndios, ci se guardase, executase lo que tenía mandado en sus hordenansas. Cómó tenia mandado que ningún becino, comendero de yndios, ni entrrrase, ni español ni mestiso ni mulato ni negro en sus pueblos y tierras ni en sus términos, cino que fuesen a las ciudades a ueir ellos. Y que se fuesen casados con las dichas yndios, lo lleuasen y que no uiuiesen mayordomos.

Porque no rresultase daños y males entre yndios, que dellos rresultaría alsamiento y se enseñarían malos uicios. Y los dichos españoles estarían amansebados y haría casta maldita de mestisos. Y no multiplicarían los dichos yndios tiste rreyno, y les forsarían a sus mugeres y hijas y se enseñarían uellacos y no obedecirían a sus caciques prencipales y se harian harrraganes y ladrones, yanaconas, bachelleres y las mugeres grandes putas y tomarían otros rresabios y malas obras. ${ }^{15}$

O extrato de texto citado sintetiza a imagem do mestiço para o cronista e aponta os atributos que justificam sua visão, as decorrências da atuação do mestiço, como as medidas que propõe para controlar a sua intervenção.

O mestiço é maldito porque ilegítimo fruto da mancebia - isto o afasta da legitimidade na sociedade hispânica, secular e religiosa. Entretanto, esta é a forma da relação entre conquistador e conquistado : a mulher indígena é tomada como manceba, sem lugar e reconhecimento entre espanhóis e fora das tradições indígenas, convivendo, co-habitando com o espanhol, conquistando espaços estranhos à tradição e interrompendo a geração de índios. Esta denún-

${ }^{15}$ POMA, op. cit., vol 2, p. 413/414. 
cia perpassa toda a estrutura argumentativa como indicação de um fator de destruição da população e das tradições, da moral e dos costumes pré-hispânicos.

A sistemática consideração da relação do nascimento do mestiço com o decréscimo da população indígena e a extinção destes evidencia que, diante da constante indicação da presença da mulher índia, na condição de mãe, para Poma o mestiço está fora do mundo índio. Sem dúvida a menção que faz em outras passagens sobre a predominância da origem étnica e social masculina para definir o lugar social da mulher aponta uma tradição a preservar, mas que deixava de ser observada sob as condições de relaxamento de práticas provocada pela intromissão de homens estrangeiros, de diferenças de expectativas e reconhecimento efetivo de papéis e lugares, pela quebra das condições históricas que até então haviam garantido as práticas tradicionais, cujas condições atuais quebravam, dificultavam e impediam.

O mestiço é maldito porque é o responsável pelo desaparecimento físico do indígena : nascem mestiços, não podem nascer índios. Os mestiços estão por todos os lados, numerosos, ameaçadores. Seus maus hábitos destroem os puros costumes anteriores, por eles e com eles as mulheres se prostituem, os homens envergonhados de suas mulheres fogem das aldeias e não produzem, e não geram filhos índios.

O mestiço é maldito porque sendo compósito do conquistador faz presente a derrota e a dominação. Sua intervenção é a presença do outro indesejado e não se pode afastá-lo, porque também é parte do nós, mas é só parte, não permite que nos reconheçamos inteiramente nele.

O mestiço é maldito porque todo o mal trazido pelo conquistador se infiltra através dele na sua própria carne e se espalha entre os puros, impedindo-os de continuarem puros, retira-lhes a potência : diminuem os índios "y no ay remedio"

Dime, autor, ¿cómo agora no multiplica los yndios y se hazen pobres?" Diré a vuestra Magestad : Lo primero, que ni multiplica porque todo lo mejor de las mugeres y donzellas lo toman los padres dotrinantes, comenderos, corregidores y españoles, mayordomos, tinientes, oficiales criados de ellos. Y ancí ay tantos mesticillos y mesticillas en este rreyno. Con collor de decille manzebado le toma y quita a las mugeres y a sus haziendas de los pobres. De todo lo dicho, de tanto agrauio y daño, se ahorcan ellos propios como los yndios Changas en Andagauyllas. Está un serrillo lleno de yndios, yndias. Quiere murir una ues queee no uerse en tanto daño. Dime, autor, ¿cómo multiplicará la gente? 
Digo a vuestra Magestad como o tengo escrito : Biuan los padres y curas u comenderos, corregidores y otros españoles y caciques principales, biuan como cristianos y como manda vuestra Magestad, cin pasar a más, y dexen gozar sus mugeres y haziendas y los dexe sus donzellas. Y no ayga tantos rreyes y justicias sobre ellos y le dexen multiplicar. Y sean castigados grauemente y quitados de los oficios y beneficios. Y porque a de conzederar que un rreyno lo pierda de tanto ualor vuestra Magestad que tanto le aya uallido se pierda y se acauen todos los yndios que ya [están despoblados. Adonde auía mil ánimas, ya no ay ciento. Y todos los biejos y biejas no pueden ya multiplicar. Aunque aya ya indios solteros, se casan com biejas que no pueden parir. Fuera desto, le aprimia con grandes trauajos y lo enquietan y lo rroban hasta quitalle las hijas y hijos y las mujeres cazadas.

Y ni ahy rremedio porque todos se aúnan : el jues, el corregidor, tiniente, comendero y mayordomos y otros españoles y mestizos y becitadores de la santa madra yglesia y uicarios y curas. Todos son contra los pobres, todos a una mano uinen en favor de los españoloes dones y doñas. De todos los pobres de ciruen; no tan solamente se siruen, cino que le entra en sus pociciones y haziendas y tierras, pastos y casas de fuerza contra su boluntad. Escriuillo es llorar. Nenguno de ellos enforma a vuestra Magestad.

La uerdad diré asserca del ualor y precio y aprouechamiento y rrenta y serucio que se a tenido y se a de tener y se pierde los yndios y se perderá todo el rreyno. A de sauer vuestra Magestad que se ualia de los yndios con lo que pagan cada tercio dos ueses en el año en plata y mays y trigo, rropa, gallina polloa y en ganados de la tierra, y otras especias. Fuera desto ciruen en las minas y plasa y en los tanbos y mesones rreales y aderesan puentes en buestro rreyno. $Y$ linpian camonis rreales y atajos y dellos salen el quinto, el di[e]smo, el pecho, la alcauala que de los mestizos y mulatos, tambiém de los españoles; no tiene tanto prouecho vuestra Magestad nenguna.

Y ancí pongo precio de mucho valor estimado y cuydadi que no se pierda esta rreyno los dichos yndios. Porque ci le quita un español y tiene quatro yndias parederas de mesticillos a las ditas mestizas lo niega nombrallo jues acohechados ni ay lugar porque son tantos y las yndias son tantas. ${ }^{16}$

${ }^{16}$ Idem, p. 896-897. 
O mestiço é maldito porque concretiza, evidencia dolorosamente a imposição, a dominação, a perda do universo conhecido.

A única forma de ser boa criatura é ser puro, é ser índio, espanhol ou negro. A única forma de conviver é segregarm, é, portanto, não interferir no universo do outro. $\mathrm{O}$ rei pode usufruir os bens do reino preservando-o na sua integridade, impedindo a difusão do mal, contendo o trânsito entre os diferentes.

Os recursos do discurso cristão são usados para rebater a proposta evangelizadora e conquistadora a partir dela mesma, das práticas que evidenciam a profunda divergência entre a prédica cristã católica e a prática da doutrina, o que acarreta profundos malefícios.

A de sauer vuestra Magestad que auía enbiado en un tiempo a los prencipales yndios de la probincia de México, diziendo que le avía envialle má padres dotrinantes para que le dotrine. Responde los prencipales que ni es menester tantos padres porque bastaua la que abía y que auían multiplicado mucho los padres que tienen muchos hijos mestizos padres. Que como ena hijos de padres, tanbién pensauan que sus hijos tanbién eran padres, y ací les llamuan a todos "padres". Y aun hasta a las mugeres les llamaron "padres"que hacía aquella casta.

A de sauer vuestra Magestad que tanbién ay muchos padres y su multiplico en este rreyno es, o propio. Y ancí ay tantos mesticillos. Ci de cada pueblo lo ajunta las donzellas y lo tiene enserrado en su casa con color de la dotrina ¿cómo no a de multiplicar tanto? Pregúnteme. vuestra magestad del remedio desto

Digo a Vuestra Sacra Católica Real Magestad, llorando y clamando, dando boses al cielo, pidiendo a Dios y a la Urgen Maria y a todos los santos y santas, ángeles. Digo que a nosotros pobres nos enbía tantos castigos y malauenturas y destruciones Dios y vuestra Magestad no permita que nos acauemos y se despueble su rreyno. ${ }^{17}$

O mestiço é maldito porque concentra, representa, simboliza a materialização da desordem que se volta contra o dominado, através de seus próprios elementos. Produto involuntário contém o descontrole da vontade em si mesmo : é mentiroso, vil, prepotente, se volta contra os seus - ou parte dos seus, os índios.

${ }^{17}$ Idem, p. 998-999. 
O mestiço amaldiçoado por Poma é o oposto do mestiço construído por Garcilaso, este, arauto de um novo mundo de conciliação, realização da possibilidade do entendimento, tradutor necessário e compreensivo entre mundos diversos.

Para Poma não há conciliação, a tradução não se viabiliza, não há compreensão entre diferentes. A fusão é o caos. O mestiço é o outro em mim, a perda da identidade, o que impede que eu me reconheça é o mal-estar. Não sendo nem um nem outro o mestiço pode se voltar contra um ou outro - é ameaça.

Um aspecto nada desprezível da estrutura da obra de Poma é a inclusão do mestiço na categoria espanhol, associado ao criollo e ao mulato. Índios e negros constituem outras categorias. A presença dos negros associa-se à dos espanhóis, mas estes são considerados como o mais baixo elemento numa classificação de reconhecimento relacional ético/étnico.

Esta inferioridade do negro pode ser referência para qualificar negativamente outras categorias, quando comportamentos individuais podem ser classificados como piores do que aqueles esperados de um negro. Este tipo de comparação é muito utilizada por Poma : um espanhol pode ser pior que um negro, o que o situaria num padrão ético absolutamente desqualificado no referencial do autor; um criollo pode ser ainda pior do que um mestiço, que já é, por si, o resumo dos defeitos humanos. Este sistema classificatório do autor permite-lhe avaliar as qualidades de cada categoria étnica definida e através dos paradigmas daí advindos avaliar os atores sociais nas suas atuações individuais.

A inclusão do mestiço na categoria espanhol, que ainda abarca criollos e mulatos não é fortuita na estrutura da construção compreensiva do processo tratado : o radical espanhol, do conquistador é o elemento central da destruição do universo indígena de referência. Poma enfatiza as distorções da estrutura colonial que destruindo o reino prejudicam o rei. Aponta a ação de maus espanhóis, cuja prática incoerente com a prédica cristã atua como destruidora da população indígena e prejudica o rei. Desconsidera os negros, tal como os espanhóis, como agentes socialmente reconhecidos. At last but not least, culpabiliza os mestiços pelo desaparecimento dos índios. Observa-se que o fator central da ação destruidora aponta para o conquistador espanhol. O mal - a destruição - decorre da intervenção externa do colonizador. O mestiço, entretanto, é resultado, mas também instrumento desta intervenção, que materializa.

Apresentando ao rei as lamentáveis condições do reino, para as quais pede providências, o cronista encaminha seus argumentos : "Conzedera que cómo lleua tanta pasencia los yndios y las yndias en esta uida de tantos males de 
españoles, padre, corregidor, mestizos y mulatos, negros y anaconas y chinaconas que les sacan la uida y las entrañas a los yndios." ${ }^{18}$

Este excerto aponta a alegada direção de argumentação usada por Poma. Observa-se a condenação conjunta de espanhóis, muito precisamente de padres e corregedores, junto ao conjunto sócio-étnico identificado com a conquista/colonização, incluindo os índios yanaconas e chinaconas, cuja posição subserviente pode ser interpretada na sua avaliação como oportunista e ilegítima. O que permitiria na estrutura argumentativa do autor a inclusão destes elementos numa identificação particular seria a ausência da prática da moral cristã como condição causante dos males apontados. Padres e corregedores, assim como outros espanhóis, que atuam em radical divergência com as normas da moral cristã, são condenados e as narrativas das circunstâncias dos atos e consequiências a estes atribuídos pelo autor sucedem-se no texto. Ganha espaço destacado a vida sexual desregrada dos padres e a sua responsabilidade na geração de inúmeros mestiços, na desorganização da sociedade e na demografia, como na violência contra as mulheres índias e sua prostituição.

O autor expõe ao rei, com minúcias, as práticas sexuais violentas de representantes da Igreja contra as mulheres índias. Na condenação destes atos e dos atos de abuso e roubo por parte dos corregedores, como dos atos reprováveis dos espanhóis, está subjacente a distância entre a pregação da moral cristã e de uma prática que dela se afasta, destruindo e confundindo os índios. Da mesma maneira a ausência da moral cristã justifica a atuação negativizada de mestiços, mulatos, negros, yanaconas, chinaconas.

A representação negativizada dos mestiços é decorrente também da prática de relações, sobretudo de contatos físicos entre os diferentes grupos, o que é sempre indesejável. Daí resulta a indefinição do pertencimento do mestiço. Assim, desprovidos de referências e lealdades, o que Poma sempre expressa na atribuição das qualidades de traidores, desleais, os mestiços se constituem sempre por indicadores negativos. $\mathrm{O}$ argumento de que não servem nem a Deus nem ao rei referenda a segregação da casta. $O$ excerto que se segue permite observar a construção do círculo de argumentos em que se destacam os elementos destruidores do reino :

Españoles/ soberbioso criollo o mestizo o mulato deste rreyno /en los pueblos

\footnotetext{
${ }^{18}$ Idem, p. 882 .
} 
Criollos : Cömo los dichos criollos que se crían con la leche de las yndias o de negras o los dichos mestizos, mulatos, son brabos y soberbioso, haraganes, mentirosos, jugadores, auarientos, de poca caridad, miserable, tranposos, enemigos de los pobres yndios y de españoles.

Y ancí son los criollos como mestizos, peor que mestizos, porque de ellos no sea a parecido seruicio ni se a escrito que aya seruido a Dios y a su Magestad que se pueda escriuirse de ellos en este rreyno ni en toda castilla. De cómo los dichos criollos son peores que mestizos y mulatos y negros y los dichos mestizos son más peores para con sus tíos y tías, madres, ermanos, ermanas carnales y parientes yndios. Son muy brabísimos y soberbiosos y le rroban y saltean en los caminos a los dichos yndios pobres, sus haziendass andan salteando en todo el rreyno. Y los dichos corregidores tienen pesadumbre muy mucho de ellos. Y cí le dejan biuir entre yndios en este rreyno, destruyrá y rrebolberá en [sic] los pueblos a los yndios deste rreyno. ${ }^{19}$

A intrincada rede de competições pela liderança das piores qualidades entre as categorias sócio-étnicas apontadas tem, todavia, o crivo do critério da classificação : a destruição dos índios. A desqualificação destas categorias está sempre relacionada à ausência da pureza. Já o criollo se desvirtua porque se alimenta de leite índio ou negro, tornando-se impuro, contaminado.

A observação da representação iconográfica do mestiço e da mestiça são elementos que contribuem para a observação de uma construção estereotipada produzida sob essa ótica de pureza/atributos positivos - impureza/atributos negativos. Aí se encontra a fusão da imagem de criollos, mestiços e mulatos, através da imagem da ação perversa sobre os índios. O desenho que se tece com o texto dá força à representação da intervenção violenta dos protagonistas.

${ }^{19}$ Idem, p. 511. 

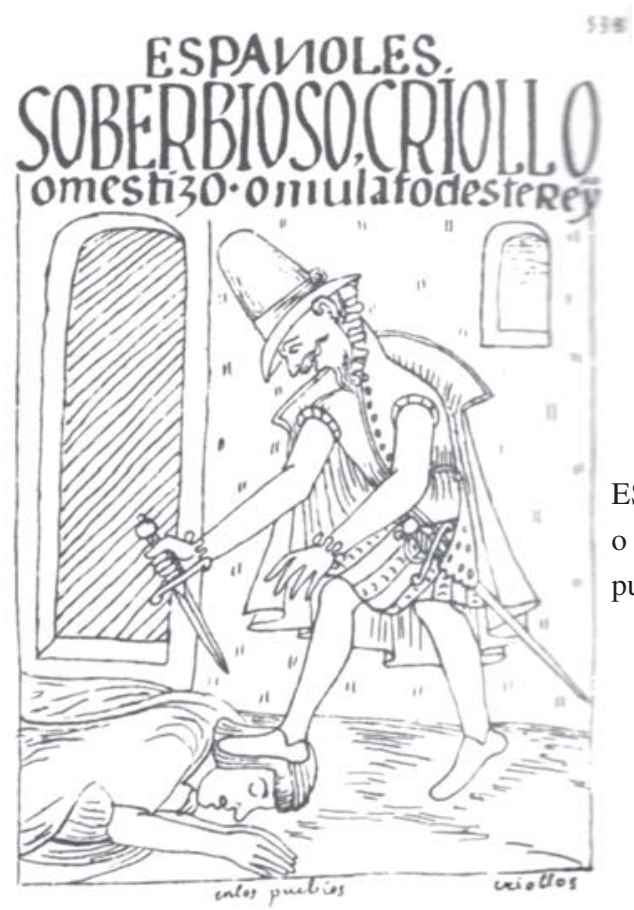

ESPAÑOLES / SOBERBIOSO CRIOLLO o mestizo o mulato deste rreyno / en los pueblos $/^{20}$

ESPAÑOLES / SOBERBIOSA CRIOLLA o mestiza o mulata deste reyno / en los pueblos $/^{21}$

${ }^{20}$ Felipe Guaman Poma de Ayala, op.cit., p.5]

${ }^{21}$ Felipe Guaman Poma de Ayala, op.cit., p.5]

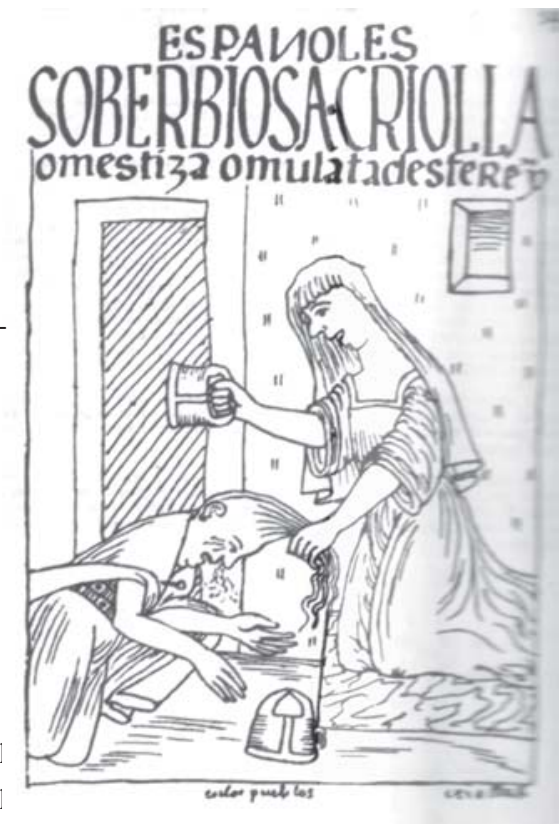




\section{Além da maldição}

As dimensões do processo de formação da sociedade colonial, a especificidade e o limite das fontes consideradas, a complexidade da obra de Poma e a insuficiência de informações contextuais, não permitem rotundas conclusões em torno das questões levantadas.

Caberia ainda indagar :

Que pretensões teria o cronista ao apresentar ao rei o que chamou de "Cronica"? Certo pretendia publicar o texto, mas com que objetivos, efetivamente?

Como entendia as relações em que se inseria e que expectativas teria com a sua peroração?

Com a larga distância entre o tempo da produção do texto e o tempo das reflexões suscitadas, é possível, talvez, ousar considerar que a Primer nиеva coronica y buen gobierno foi, entre outras possibilidades, o registro de uma constatação dolorosa do desaparecimento assistido e vivenciado de um mundo que à medida que se perdia mais parecia ter sido seguro e perfeito.

Como ay muy famosos ladrones y jugadores, rrifianes, salteadores y mintirrisos, peor que negros, españoles como en Castilla en este rreyno. Porque em tiempos de los Yngas no teniam ouertas ni caxas ni serradura, llaues. Teníam sus casas serrado con palillos. Agora que grandicímos ladrones que desserraxan y hurtan y rroban los yndios como españoles y peor que negros. En esta uida los yndios que no tienan oficio lo que no trauajan quiere y entiende sólo bestir y enborrachar y jugar a los naypes entre ellos con los españoles y negros en este rreyno. Conzedera. Conzedera cómo son tan peresosos los yndios y las yndias en esta uida. Son holgasanes yanaconas, chinaconas porque les enseña los españoles y españolas, trayéndole por yanacona (criado) o por muchacho o chinacona (criada), ama o cosener, panadera, despensera. Y ancí se pierde y se hazen muy grandes putas y paren mestisos. Y aní se despuebla los pueblos y se acauan los yndios y multplican mestisos. Cin prouecho pierde su Mageestad deste rreyno. Conzedera desto.

Conzedera cómo biuen mal cazados los yndios en este rreyno en esta uida. Que en tiempo de los Yngas no auía adúlteras, putas, mal cazadas. Agora lo ay por las causas ciguientes : El primero, como uen a los españoles; el segundo, que son las grandes borrachas las mugeres y comen rregalos y ancí enciende la luxúria; el terzero, como uen al corregidor, padre, comendero, españoles estar amansebado quiere ellos 
también; el quarto, le fornica de fuersa a sus mugeres y hijas, donzellas y no hay rremedio, y ancí ya después las dichas yndias muy grandes putas y no hay castigo. Conzedera esto.

Ci las donzellaslo desuirga y lo toma para cí todas hasta que sean medias uiejas con color de la dotrina y despeués de ser uiexa, pasados de cinquenta años que en su uida ya no hará hijo, que la sobra que dexa las cojas feas, emfermas, mancas, tollidas yndias lo dexa. Y ací no multiplica ni multiplicará los yndios, mas multiplica los mestizos, andan en áuito de yndios'.

Por esta rrazón, vuestra Magestad deue mandar y suspender de conoser de causas de pecados ciueles y criminales, cino que la misma audiencia o un jues que para ello vuestra Magestad señalare le connoca y que rrecida en lo Rey de Lima y que con el contrario querelante acuda personalmente parra el seruicio de Dios y de uuestra corona rreal y bien de los pobres de Jesucristo.

Le dé vuestra Magestad esta prouición sobornadas y rremitida a la corte de bueso rreyno adonde precide bueso bizorrey y encargando a todos los yndios de bueso rreyno, principales que defienda a sus yndios. Y ancí vuestra Magestad servirá Dios y bien aumento de los yndios deste rreyno. Conzedera vuestra Magestad de todo ello, bien de los yndios. ${ }^{22}$

A perda das referências que anteriormente garantiam o prestígio, a honra e a dignidade, o mundo do conhecido, de possíveis expectativas era acompanhada pela intromissão de inesperados elementos. A destruição dos índios se efetivava pela desorganização das relações entre os sexos. A perda do controle e do poder de gerar filhos índios é crucial na avaliação de Poma. Sem o controle das mulheres não há controle da geração de filhos e o aumento de filhos de espanhóis, em detrimento do nascimento de índios sinaliza o desaparecimento dos índios. A viabilidade da sobrevivência dos índios está na inviabilidade do nascimento de mestiços. $\mathrm{O}$ aumento crescente de mestiços torna-se assustador, tanto por si só, como pela forma em que ocorre : as mulheres tornam-se adúlteras, se fazem grandes putas e parem mestiços. A geração de mestiços está aqui, sempre associada à má conduta de mulheres índias, do abuso do homem espanhol. Sempre desqualifica a mulher. Ao mesmo tempo desqualifica o mes-

${ }^{22}$ Idem, pp. 871872. 
tiço. Aqui não se evoca simplesmente o argumento jurídico da ilegitimidade, mas o caráter moral em que se sustenta a própria ilegitimidade. Este argumento moral radicaliza a argüição da dominação e expõe o caráter da conquista. Expõe o mestiço na sua trágica condição de elemento de consolidação da conquista. Poma atribui ao mestiço, entretanto, uma autonomia de destino que ele não pode ter, na correlação das forças sociais que o inventaram - outra trágica condição em que se encontra ele restringido.

A adoção de referenciais cristãos, o domínio possível das novas formas de comunicação e expressão, a nova língua, embora convivendo com as originárias, a escrita, partilhando com o desenho a produção do registro, foram instrumentos que Poma não desdenhou e soube utilizar. Para preservar a memória da sua inconformidade com os rumos da história aliou os recursos disponibilizados pelas culturas em confronto.

Nesta construção destaca-se o papel que atribui ao mestiço/mestiça, referenciados à intervenção espanhola, como sujeito e instrumento da destruição demográfica e cultural do mundo andino. Daí a maldição do mestiço, o bastardo, o indesejado, o mal, o outro infiltrado. O desejo de afastar o outro está manifesto na valorização e recomendação da separação dos espaços, evitar a contaminação, impedir que o mal se alastre.

Embora Poma tenha, na sua narrativa, apontado diversas causas e protagonistas para o processo de destruição do universo andino, como já se viu, destaca e enfatiza o papel dos mestiços. Estes constituem casta maldita.

A conotação jurídico-religiosa implícita na afirmação imprime ao argumento um caráter definitivo e definidor, porque se funda coerentemente com a valorização da moral cristã que sustenta o arcabouço da argumentação. Coincidindo com o argumento hispânico que sustenta a segregação de mestiços, justificativa da negação de possíveis direitos na república dos espanhóis, o argumento da ilegitimidade alcança força no discurso. Confere relevância e legitima à maldição levantada pelo índio.

Uma irônica manifestação do acaso, ou o destino fez com que enquanto o texto de Poma permanecia inédito, desconhecido durante séculos, os mestiços se multiplicassem pelo continente. Teria se cumprido a maldição? Seriam os mestiços condenados à maldição ou teriam sido eles mesmos, como aquele(s) que os nomeou(aram), vítimas das perversas condições de conquista e da dominação?

Contudo, o universo andino demonstrou a sua vitalidade, sobrevivendo física e culturalmente num mundo que intensificou as trocas, as intervenções e o 
confronto. Os contingentes étnicos que se reuniram nesta América pelos efeitos da expansão européia da primeira mundialização prosseguiram na sua trajetória.

As inquietações provocadas pela exacerbação do confronto e da intolerância, que já marcaram a entrada do novo século, constituem um motivo relevante para que se enfrente as questões da dominação, da difícil convivência com o diverso e para que as condições para a invenção de maldições e malditos possam ser enfrentadas.

\section{Bibliografia}

ADORNO, Rolena. Cronista y príncipe. La obra de don Felipe Guamán Poma de Ayala. Lima : Fondo Editorial de la Pontificia Universidad Católica del Perú, 1992. Segunda edición.

ARES QUEJIA, Berta. El papel de mediadores y la construcción de un discurso sobre la identidad de los mestizos peruanos (siglo XVI). In: ARES QUEIJA, Berta \& GRUZINSKI, Serge. Entre dos mundos : fronteras culturales y agentes mediadores. Sevilla :s/ed., 1997, p. 37-59.

GRUZINSKI, Serge. Entre dos mundos : fronteras culturales y agentes mediadores. Sevilla : s/ed.,1997.

COOK, Noble David. Padrón de los indios de Lima en 1613. Lima : Universidad Nacional Mayor de San Marcos, 1968.

DAYRELL, Eliane Garcindo. $O$ índio e o imaginário americano : enfrentamento, ameaça ou solução?. Texto apresentado no Colóquio Internacional ADLAFAFSSAL-El Indio como sujeto y objeto de la Historia Latinoamericana - pasado y presente. Universidad Católica de Eichstätt, 25-28 de outubro de 1995.

GRUZINSKI, Serge. O pensamento mestiço. São Paulo : Cia. das Letras, 2001.

HERNÁNDEZ, Max. Memoria del bien perdido. Conflicto, identidad y nostalgia en el Inca Garcilaso de la Vega. Madrid : Sociedad Estatal Quinto Centenário, 1991.

LAVALLÉ, Bernard. Las promesas ambiguas - ensayos sobre el criollismo colonial en los Andes. Lima : Pontifícia Universidad Católica del Perú/Instituto RivaAgüero, 1993.

LOCKHART, James. El mundo hispanoperuano. México : Fondo de Cultura Económica, 1982.

LÓPEZ-BARALT, Mercedes. Icono y conquista : Guamán Poma de Ayala. Madrid : Hiperión, 1988, p. 282. 
MAHN-LOT, Marianne. A Conquista da América Espanhola. Campinas : Papirus, 1990. MÖRNER, Magnus. Le Métissage dans l'histoire de l'Amérique Latine. Paris : Fayard, 1971.

POMA DE AYALA, Felipe Guaman. El primer Nueva Corónica y Buen Gobierno. Edición crítica de John V. Murra y Rolena Adorno. México : Siglo XXI, 1980. 3v. SÁ, Eliane Garcindo. Mestiço : entre o mito a utopia e a História. Rio de Janeiro, 2001 - versão impressa.

VEGA, Inca Garcilaso de la. Historia General del Perú - Segunda Parte de los Comentarios Reales de los Incas. Buenos Aires : Emecé, Tomo I, 1944. Comentarios Reales. $1^{\text {a }}$ parte. Caracas : Fundación Biblioteca Ayacucho, 1985. 